\title{
Green Carbon Nanofiber Networks for Advanced Energy Storage
}

\author{
Jiayuan Wei, Shiyu Geng, Olli Pitkänen, Topias Järvinen, Krisztian Kordas,* and Kristiina Oksman*
}

Cite This: ACS Appl. Energy Mater. 2020, 3, 3530-3540

Read Online

ABSTRACT: Energy storage devices such as supercapacitors of high performance are in great need due to the continuous expansion of digitalization and related devices for mobile electronics, autonomous sensors, and vehicles of different kinds. However, the nonrenewable resources and often complex preparation processes associated with electrode materials and structures pose limited scale-up in production and difficulties in versatile utilization of the devices. Here, free-standing and flexible carbon nanofiber networks derived from renewable and abundant bioresources are demonstrated. By a simple optimization of carbonization, the carbon nanofiber networks reach a large surface area of $1670 \mathrm{~m}^{2} \mathrm{~g}^{-1}$ and excellent specific gravimetric capacitance of $\sim 240 \mathrm{~F} \mathrm{~g}^{-1}$, outperforming many other nanostructured carbon, activated carbon, and even those decorated with metal oxides. The remarkable electrochemical performance and flexibility of the green carbon networks enable an all-solid-state supercapacitor device, which displays a device capacitance of $60.4 \mathrm{~F} \mathrm{~g}^{-1}$ with a corresponding gravimetric energy density of 8.4 Wh kg-1 while maintaining good mechanical properties.

KEYWORDS: green carbon, electronics, energy storage, lignin, electrospinning

\section{INTRODUCTION}

Energy storage devices with high energy/power densities, excellent structural integrity, and long-term reliability are of great demand due to their current and future exploitation in electronic devices applied in portable appliances, remote and/ or self-powered sensors, and vehicles of different kinds. ${ }^{1,2}$ Compared to batteries and pseudocapacitors, electrostatic supercapacitors achieve high charge/discharge rates, remarkable power densities, and outstanding long cycle life. ${ }^{3-6}$ Carbon-based electrodes with their excellent conductivity and accessible surface area as well as low density offer not only high specific electrical double-layer capacitances but also significantly reduced cost, in contrast to nanostructured metal oxides and metal sulfides. ${ }^{7}$ The commonly considered carbon materials include carbon black, graphene, carbon nanotubes, and onions as well as their derivatives and composites with outstanding overall performance. ${ }^{5,8-12}$ However, nonrenewable resources and the complex preparation processes of these materials pose significant obstacles to meet stringent environmental requirements and, in some cases, disable large-scale manufacturing. On the other hand, biocarbons derived from abundant and renewable natural resources may alleviate the burden of the environmental footprint of conventional synthetic carbon nanomaterials and could also help several industries to valorize side-stream organic wastes and residues. $^{13-15}$

Lignin is the second most abundant natural polymer on earth, and together with cellulose and hemicellulose, lignin is one of the main components in wood. ${ }^{16}$ However, despite its great abundancy and easy accessibility in nature, lignin has been highly underutilized for decades. ${ }^{17}$ There is more than 50 million tons of lignin produced annually by the pulping and paper-making process, but most of it is burned for low-value thermal energy. ${ }^{18-20}$ Although significant efforts have been made to advance the production of lignin-based materials and applications, as of today only $<2 \%$ of the produced lignin is valorized and used for example in adhesives and foaming agents. ${ }^{18-20}$ It is also believed that making good use of lignin will enable a biofuel economy to be competitive with oil refining as lignin is now only a low-value byproduct in the biorefinery. ${ }^{14,21,22}$ Excitingly, because of the merits of low price, high carbon content, and no toxic emission during the process, lignin can be a fascinating raw material for the production of high-quality biocarbons with well-tailored functions and properties. ${ }^{13,14,23,24}$

Combining electrospinning and carbonization process, lignin can be converted to carbon nanofiber networks with very large surface area that endows their great potential to be used in energy storage applications. Until now, only a very limited amount of studies focused on the lignin-derived carbon nanofiber networks (LCNs) without unleashing the full potential of the materials. ${ }^{23,25-37}$ The first study of electrospinning of lignin and its conversion to carbon nanofibers was

Received: January 12, 2020

Accepted: April 2, 2020

Published: April 2, 2020 
a
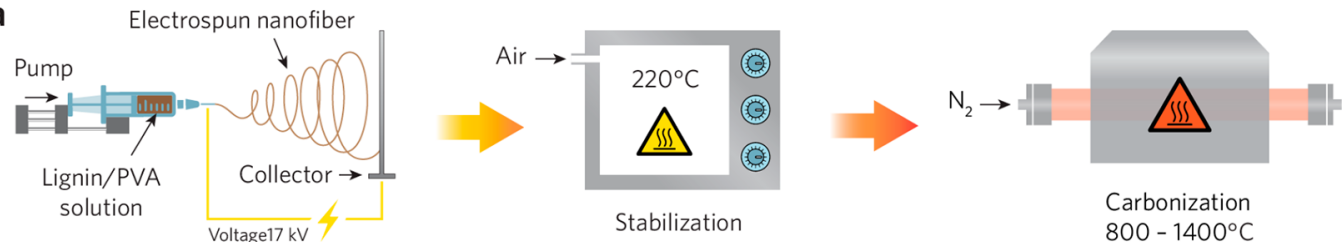

b
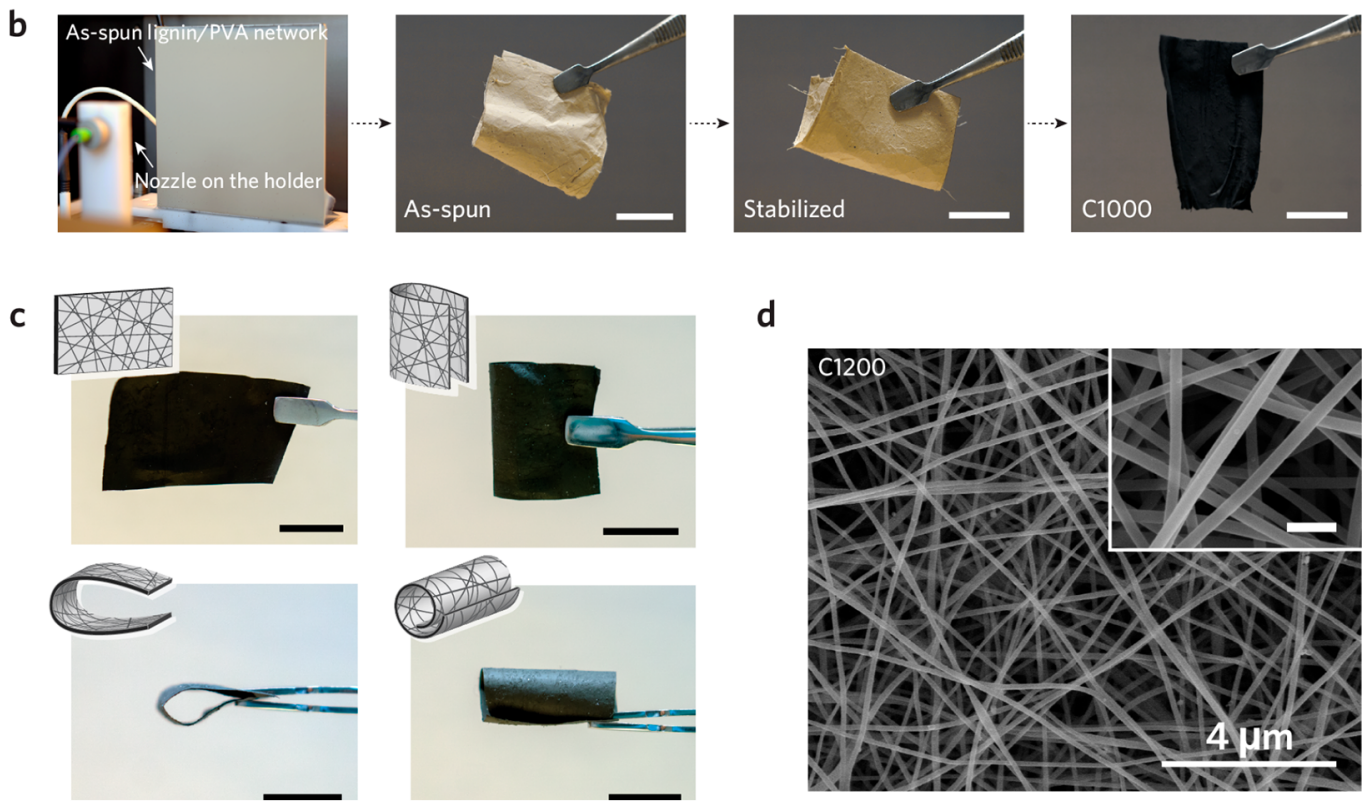

d

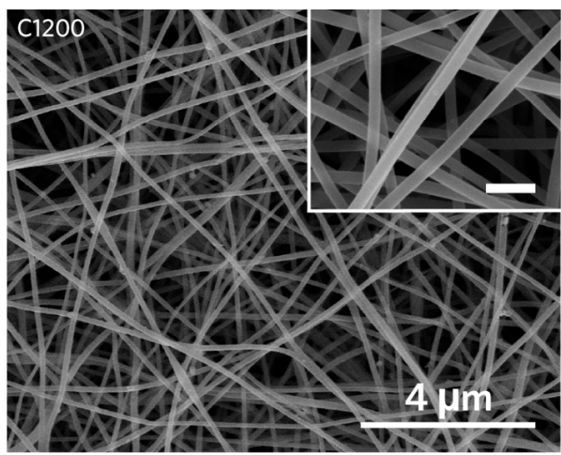

Figure 1. Synthesis and the demonstration of lignin-derived carbon nanofiber networks. (a) Schematic of the synthesis process of the carbon nanofiber networks. (b) Photographs of the electrospinning setup with an as-spun lignin/PVA network on a $20 \times 20 \mathrm{~cm}^{2}$ collector as well as illustrations of the as-spun, stabilized, and C1000 networks. Scale bars: $20 \mathrm{~mm}$. (c) Showcases for the flexibility of the free-standing C1000 carbon network. Scale bars: $15 \mathrm{~mm}$. (d) SEM images showing the microstructure of C1200 networks. Scale bar of the inset image: $500 \mathrm{~nm}$.

published in 2007 by Lallave et al., ${ }^{25}$ where a high-carboncontent (94.3\%) and high-yield (31.6\%) carbon nanofiber network was prepared via the electrospinning of organosolv lignin followed by carbonizing the electrospun network at 900 ${ }^{\circ} \mathrm{C}$. In 2013, Wang et al. first proposed the potential application of LCNs as anode materials used in lithium ion batteries. ${ }^{27}$ The obtained carbonized organosolv lignin/poly(ethylene glycol) electrospun network exhibited an excellent specific capacity of up to $445 \mathrm{~mA} \mathrm{~h} \mathrm{~g}$, which is comparable with that of neat polyacrylonitrile-derived carbon fibers. At the same time, Lai et al. carbonized electrospun alkali lignin/ poly(vinyl alcohol) (PVA) nanofiber networks at $1200{ }^{\circ} \mathrm{C}$ and used them as electrodes in supercapacitors with a specific capacitance of $64 \mathrm{~F} \mathrm{~g}^{-1}$. ${ }^{28}$ Later, $\mathrm{Ma}$ et al. reported that the conductivity of electrospun and carbonized lignin/PVA fibers was increased by surface decoration with $\mathrm{MnO}_{2}$ nanowhiskers, and the specific capacitance was increased from $4.5 \mathrm{~F} \mathrm{~g}^{-1}$ for electrospun lignin-based carbon fibers to $83.3 \mathrm{~F} \mathrm{~g}^{-1}$ with the $\mathrm{MnO}_{2}$ surface decoration as a result of its pseudocapacitive nature. ${ }^{35}$ Ago et al. activated electrospun alkali lignin/PVA fibers using $\mathrm{KOH}$ prior the carbonization process, which resulted in a high mesoporosity and specific surface area (SSA, $2005 \mathrm{~m}^{2} \mathrm{~g}^{-1}$ ) for the fibers. The fibers tested in a threeelectrode setup showed a specific capacitance of up to $205 \mathrm{~F}$ $\mathrm{g}^{-1}$, which was the highest for any lignin-derived carbon fiber electrode without additives. ${ }^{33}$

According to our previous study, ${ }^{38}$ the carbon structure and elemental composition of the LCNs are significantly influenced by their carbonization conditions, which would further affect their electrochemical properties. However, to the best of our knowledge, no systematic studies have been done to reveal the effects of carbonization conditions on the LCNs used for electrodes in supercapacitors. Therefore, in this study, we systematically analyze the effect of different carbonization temperature on the LCNs to optimize their electrochemical properties without any additional activations or additives. To demonstrate that our free-standing and high-performance LCNs can be easily integrated into flexible devices, an allsolid-state, binder- and separator-free supercapacitor has been developed for the first time with the LCN electrodes, suggesting their possible utilization in portable/wearable and sustainable electronic applications.

\section{RESULTS AND DISCUSSION}

The synthesis process of the LCNs studied in the present work is shown in Figure 1a. A kraft lignin/PVA aqueous solution (weight ratio of $75 / 25$ ) with a viscosity of $59.3 \mathrm{mPa} \cdot \mathrm{s}$, a conductivity of $17.0 \mathrm{mS} \mathrm{cm} \mathrm{cm}^{-1}$, and a $\mathrm{pH}$ of 8.9 was electrospun at a voltage of $17.0 \mathrm{kV}$ to produce the lignin/PVA nanofiber networks. The as-spun networks were then stabilized at $180{ }^{\circ} \mathrm{C}$ for $16 \mathrm{~h}$ and then at $220{ }^{\circ} \mathrm{C}$ for $8 \mathrm{~h}$ in air. During the stabilization process, thermal-induced cross-linking which forms carbonyl and carboxyl structure occurred to prevent the nanofibers from softening during the following carbonization process. ${ }^{39}$ The exact reactions are, however, unclarified. Finally, the stabilized nanofiber networks were carbonized at 
Table 1. Elemental Compositions of As-Spun, Stabilized, and C800-1400 Networks According to SEM-EDX and XPS as Well as SSA and Average Pore Size for the C800-1400 Networks

\begin{tabular}{|c|c|c|c|c|c|c|c|c|c|c|}
\hline \multirow[b]{2}{*}{ sample coding } & \multicolumn{4}{|c|}{ SEM-EDX } & \multicolumn{4}{|c|}{ XPS } & \multirow[b]{2}{*}{$\mathrm{SSA}\left[\mathrm{m}^{2} \mathrm{~g}^{-1}\right]$} & \multirow[b]{2}{*}{ pore size $[\mathrm{nm}]$} \\
\hline & $\mathrm{C}$ [at. \%] & O [at. \%] & $\mathrm{Na}[$ at. \%] & $\mathrm{S}$ [at. \%] & $\mathrm{C}$ [at. \%] & $\mathrm{O}$ [at. \%] & $\mathrm{Na}$ [at. \%] & $\mathrm{S}$ [at. \%] & & \\
\hline as-spun & 69.6 & 21.8 & 5.2 & 3.5 & 62.1 & 31.2 & 5.1 & 1.6 & & \\
\hline stabilized & 65.3 & 27.5 & 4.4 & 2.7 & 62.9 & 30.5 & 5.0 & 1.6 & & \\
\hline C800 & 87.6 & 7.4 & 4.1 & 0.9 & 61.5 & 23.9 & 14.1 & 0.6 & 797 & 2.3 \\
\hline $\mathrm{C} 1000$ & 94.8 & 3.6 & 0.9 & 0.7 & 82.9 & 11.3 & 5.2 & 0.6 & 946 & 2.1 \\
\hline C1200 & 97.7 & 2.1 & 0.2 & & 96.3 & 3.7 & & & 1672 & 1.5 \\
\hline C1400 & 99.0 & 1.0 & & & 97.9 & 2.1 & & & 1419 & 2.2 \\
\hline
\end{tabular}

a

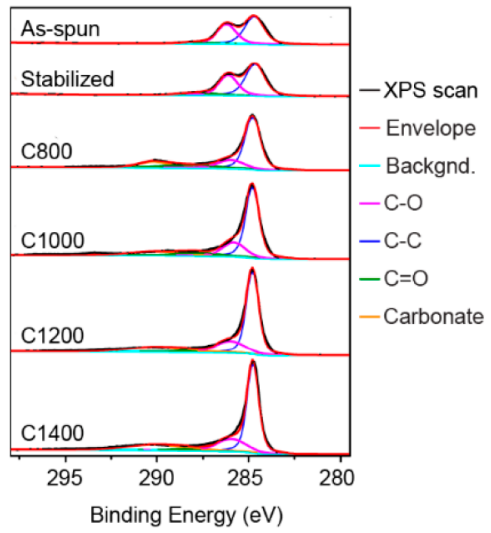

b

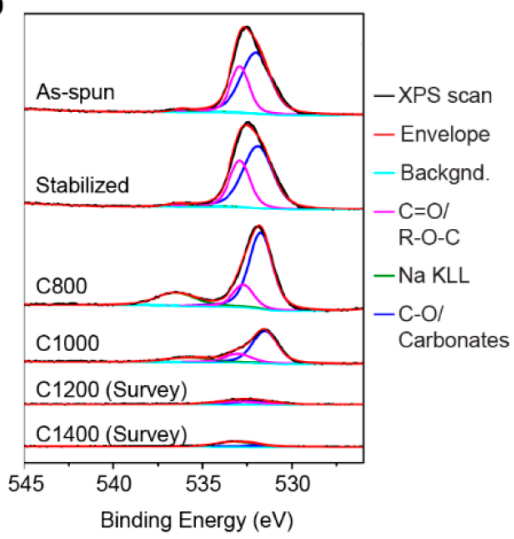

C

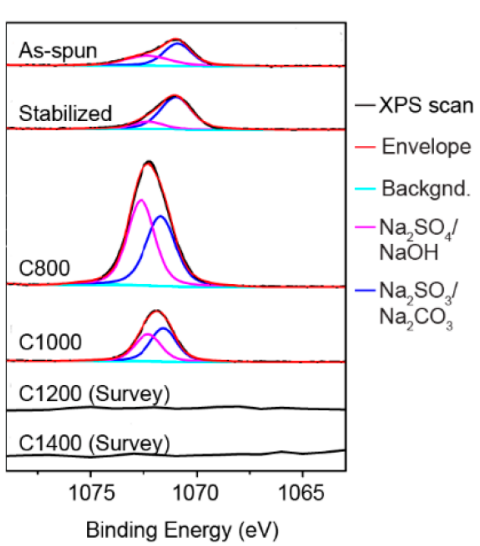

Figure 2. XPS data and fitted peaks measured from (a) C 1s, (b) O 1s, and (c) Na 1s spectral area of the as-spun, stabilized, and C800-1400 networks.

different temperatures $\left(800,1000,1200\right.$, and $\left.1400{ }^{\circ} \mathrm{C}\right)$ in a nitrogen atmosphere for $1 \mathrm{~h}$. The obtained LCNs are denoted as C800, C1000, C1200, and C1400, respectively. Representative photographs of the electrospinning setup as well as the asspun, stabilized, and C1000 networks are illustrated in Figure 1b. Clearly, the stabilization and carbonization treatments did not affect the integrity and free-standing character of the networks, and the synthesized LCNs possess excellent mechanical flexibility as they can be bent or rolled into different shapes without a permanent irreversible deformation (Figure 1c and Movie S1).

The microstructures of the as-spun and stabilized networks as well as LCNs were characterized by scanning electron microscopy (SEM) as displayed in Figure 1d and Figure S1 with the corresponding distribution histograms of the nanofiber diameter shown in Figure S2. The SEM images illustrate that the as-spun lignin/PVA network was dense and composed of randomly oriented smooth nanofibers, and the stabilization process retained the microstructure of the network intact. After carbonization at different temperatures, the nanofiber networks were still maintained with rarely seen fiber breakage, indicating that great quality of LCNs can be obtained through our synthesis process. The diameter of the nanofibers remained the same after stabilization $(182 \pm 27 \mathrm{~nm}$ vs $181 \pm 36 \mathrm{~nm}$ ), but it decreased significantly with increasing carbonization (down to $100 \pm 23 \mathrm{~nm}$ in C1400) due to the weight loss of the materials during carbonization. Notably, as shown in the inset SEM image of C800, some roughness with dot-like feature had developed on the nanofiber surface, probably because of the presence of inorganic moieties in the lignin $\left(\mathrm{NaOH}, \mathrm{Na}_{2} \mathrm{SO}_{3}, \mathrm{Na}_{2} \mathrm{SO}_{4}\right.$, and $\left.\mathrm{Na}_{2} \mathrm{CO}_{3}\right)$. The smoothness of the nanofiber surfaces of $\mathrm{C} 1200$ and $\mathrm{C} 1400$ was regained as shown in their inset SEM images of the corresponding materials, which could be attributed to the gasification of such inorganic compounds at higher temperatures. $^{40}$

The changes of elemental composition of the lignin/PVA networks occurred during stabilization and carbonization were assessed by using energy-dispersive $\mathrm{X}$-ray spectroscopy (EDX) and X-ray photoelectron spectroscopy (XPS). The results are summarized in Table 1, Figure 2, and Figures S3 and S4. According to the EDX data, carbon and oxygen dominated the chemical composition of the as-spun and stabilized network with a slightly higher oxygen content in the latter due to a minor oxidation of the nanofibers during stabilization process. ${ }^{41}$ In the LCNs, the carbon content gradually increased from 87.6 to 99.0 at. \%, while the oxygen content decreased from 7.4 to 1.0 at. \% with increasing carbonization temperature. In addition to carbon and oxygen, sodium and sulfur also appeared in the as-spun and stabilized networks due to chemical reactions introducing sulfur to lignin as well as residues of chemicals in the Kraft process. The sodium and sulfur contents in the LCNs decreased gradually with increasing carbonization temperatures due to the formation of volatile compounds and became undetectable in C1400.

XPS gave similar results for the as-spun and stabilized networks compared to EDX (Table 1). However, a notably higher amount of oxygen as well as sodium was detected in C800 and C1000, which should be arisen from the difference of the detecting depth between XPS (up to $10 \mathrm{~nm}$ ) and EDX (several micrometers). ${ }^{42,43}$ This can be related to the microscopy results shown in Figure S1 and Figure 3a where plenty of dot-like features covered the surface of C800, implying that these features contained a great amount of sodium/oxygen-rich components, resulting in a significant increase in the sodium and oxygen content in the XPS data. 

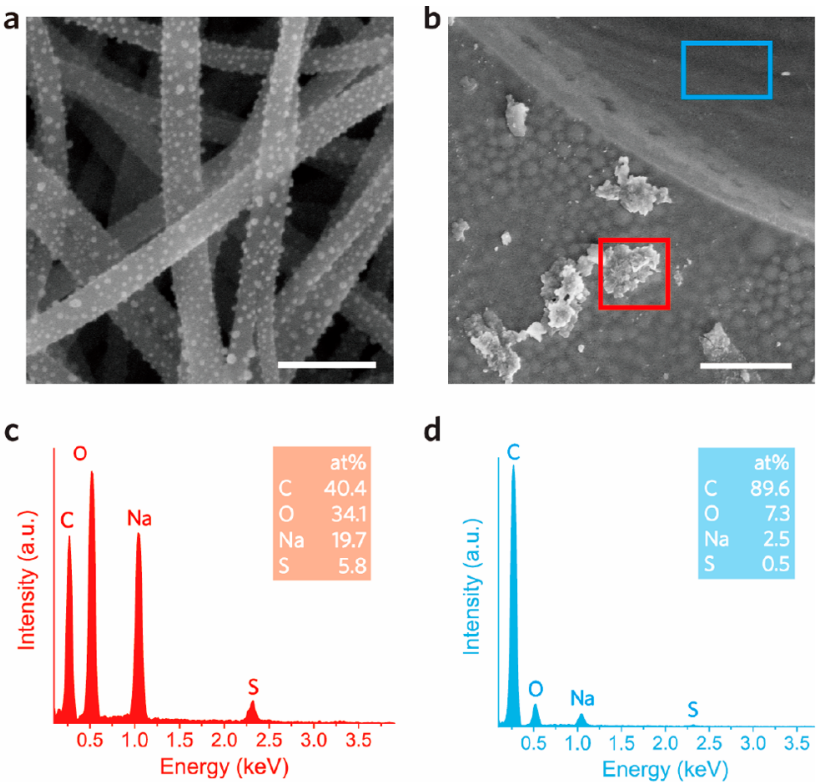

d

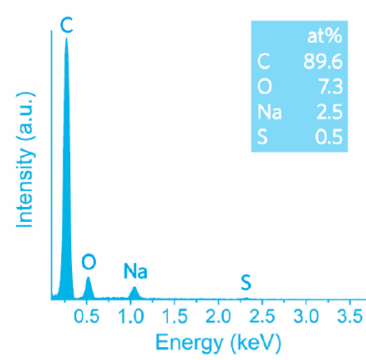

Figure 3. (a) Magnified SEM image of C800 showing the dot-like features on the surface. Scale bar: $500 \mathrm{~nm}$. (b) SEM image of the lignin-based carbon film with a fracture surface on the upper right corner. The elemental composition of the dot-like feature (red) as well as the fracture surface (blue) was analyzed. Scale bar: $5 \mu \mathrm{m}$. (c, d) EDX spectra of (c) the thin dot-like feature on the surface and (d) the fracture surface of the casted carbonized film.

Because the dot-like structure on the nanofibers is rather small compared to the size of the X-ray beam, it is difficult to locally analyze their elemental composition by either technique. Thus, a casted film was prepared from the same lignin/PVA solution and then stabilized and carbonized at the same conditions as the $\mathrm{C} 800$ to further investigate the reason for the different elemental composition results obtained from EDX and XPS. As shown in Figure $3 b$, the casted carbonized film also demonstrated surface features but much larger than those on the C800 nanofibers (Figure 3a), so the localized analysis of such features using EDX is possible. The EDX results illustrate that the area with the surface features showed much higher oxygen and sodium content (Figure 3c) compared to the neat fracture area (Figure 3d), which is consistent with the XPS and the EDX data of the LCNs shown in Table 1, respectively. To specifically measure the elemental composition of the surface feature, a large particle (size is around $5 \mu \mathrm{m}$ ) was selected to be scanned, and the result is shown in Figure S5. It was found that in the selected particle there were 50.9 at. \% of oxygen, 33.0 at. \% of sodium, 14.6 at. \% of carbon, and 1.5 at. \% of sulfur. This composition suggests that the surface features were mainly contributed by $\mathrm{Na}_{2} \mathrm{CO}_{3}$ with a small amount of $\mathrm{Na}_{2} \mathrm{SO}_{4}$. The disagreement between SEM-EDX and XPS gradually decreased and vanished as the carbonization temperature increased and the dot-like feature disappeared.

The SSA and pore size of the LCNs were also varied significantly with the carbonization temperature (Table 1 and Figures S6 and S7). According to Table 1, all LCNs exhibited superb SSA which increased significantly from $797 \mathrm{~m}^{2} \mathrm{~g}^{-1}$ (C800) to $1672 \mathrm{~m}^{2} \mathrm{~g}^{-1}$ (C1200) with the increase in carbonization temperature from 800 to $1200{ }^{\circ} \mathrm{C}$. The pore size of the corresponding LCNs deceased from 2.3 to $1.5 \mathrm{~nm}$, indicating that the formation of gases from the non-carbon elements in the lignin/PVA networks favored the development of micropores. ${ }^{44}$ However, C1400 had a lower SSA (1419 $\mathrm{m}^{2}$ $\left.\mathrm{g}^{-1}\right)$ and a larger pore size $(2.2 \mathrm{~nm})$ than C1200, which implies that some micropores merged into larger pores at $1400{ }^{\circ} \mathrm{C}$. ${ }^{45}$ The pore size distribution results shown in Figure S7 illustrate a similar trend, in which a larger amount of micropores were detected in the LCNs carbonized at higher temperature up to $1200{ }^{\circ} \mathrm{C}$ while the amount was reduced in $\mathrm{C} 1400$ and more mesopores appeared.

The thermal stability of the as-spun, stabilized, and carbonized networks from 25 to $1000{ }^{\circ} \mathrm{C}$ were studied by using thermogravimetric analysis (Figure 4a,b). After the evaporation of moisture, the as-spun network began to degrade at $\sim 150{ }^{\circ} \mathrm{C}$, whereas the degradation onset of the stabilized network appeared at $\sim 180{ }^{\circ} \mathrm{C}$ (Figure $4 \mathrm{a}$ ). Moreover, the asspun network exhibited a sharp derivative weight loss peak located at $\sim 280^{\circ} \mathrm{C}$ which was absent in the stabilized network. The possible reason is that the hydroxyl groups of PVA reacted with each other or with active groups in lignin during the stabilization process, ${ }^{46,47}$ leading to a better thermal stability of the stabilized network. As the temperature increased, both asspun and stabilized networks underwent further chemical changes, first due to the scission of ether bonds at $300-350{ }^{\circ} \mathrm{C}$ followed by the cleavage of the $-\mathrm{CH}_{3} \mathrm{O}$ (methoxy) groups on the lignin aromatic rings $\left(450{ }^{\circ} \mathrm{C}\right)$, resulting in the formation of polycyclic aromatic hydrocarbons (above $650{ }^{\circ} \mathrm{C}$ ). ${ }^{48,49}$ The thermal stability of all LCNs was very good as shown in Figure a

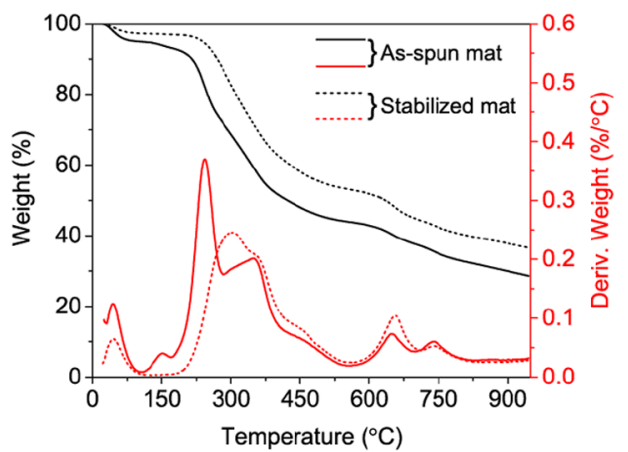

b

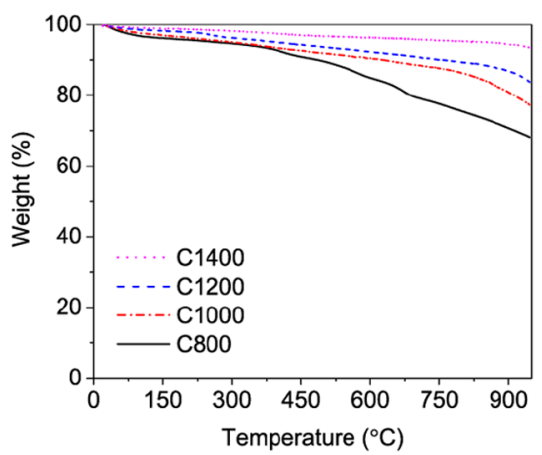

C

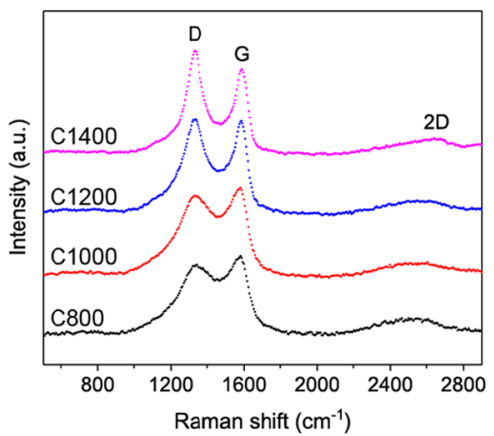

Figure 4. Thermogravimetric analysis of the (a) as-spun, stabilized, and (b) C800-1400 networks in a $\mathrm{N}_{2}$ atmosphere. (c) Raman spectra of C800-1400 carbon nanofiber networks. 
a
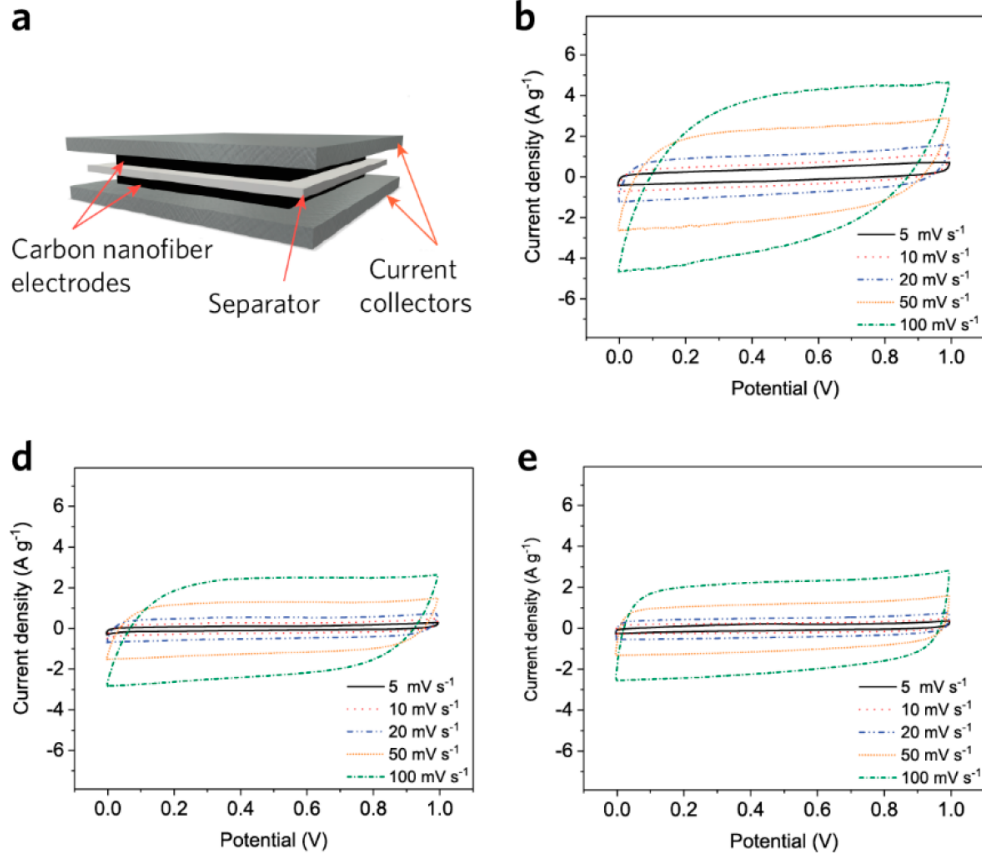

e

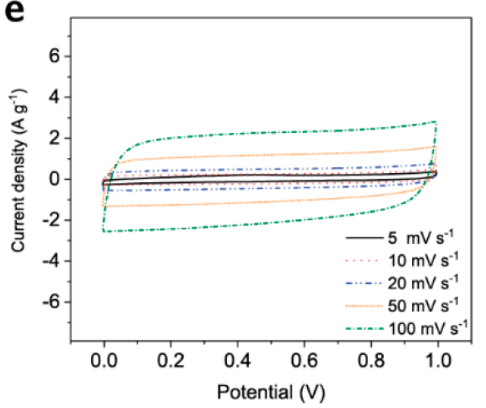

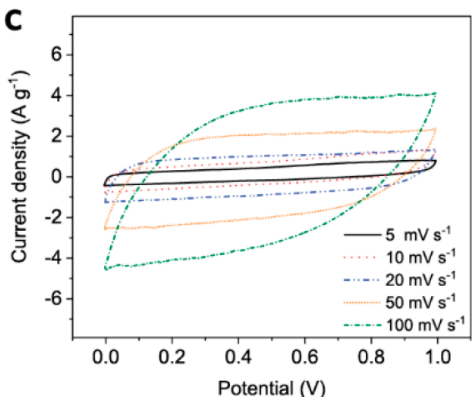

f

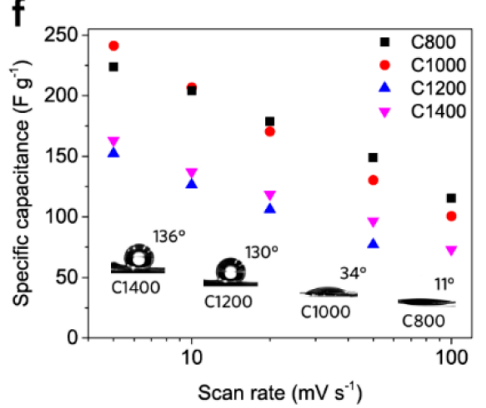

Figure 5. Electrochemical performance of the LCNs in an aqueous $6 \mathrm{M} \mathrm{KOH}$ electrolyte. (a) Schematic of the two-electrode setup used in the electrochemical measurements with the liquid electrolyte. (b-e) Cyclic voltammograms of the SC-L with (b) C800, (c) C1000, (d) C1200, and (e) C1400 electrodes at a scan rate of $5-100 \mathrm{mV} \mathrm{s}^{-1}$. (f) Specific capacitances of the C800-1400 networks at different CV scan rates and their corresponding contact angles with the electrolyte.
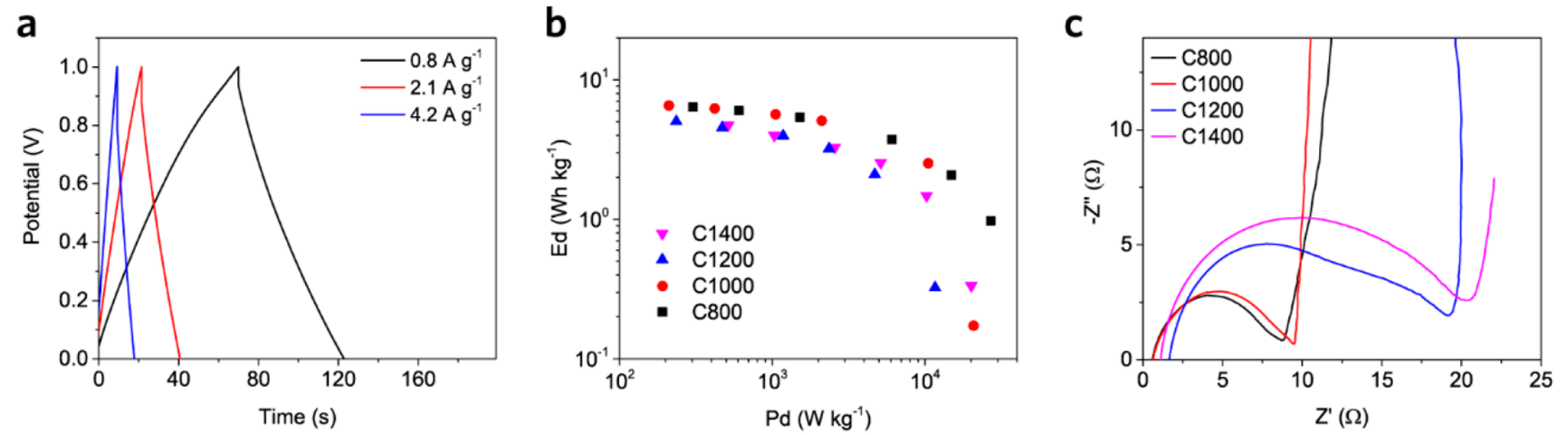

Figure 6. (a) Galvanostatic charge-discharge curves of the SC-L with C1000 electrodes under different current densities. (b) Ragone plot of the calculated energy and power densities for the SC-Ls in charge-discharge measurements. (c) Nyquist diagrams measured with electrochemical impedance spectroscopy of the SC-Ls for C800-1400 electrodes.

$4 \mathrm{~b}$, and it improved with increased carbonization temperature due to the higher carbon content.

Figure $4 \mathrm{c}$ shows the Raman spectra for the LCNs, and all LCNs exhibited characteristic Raman bands of carbon materials (D, G, and 2D bands). ${ }^{50}$ Results from transmission microscopy which were reported in our previous study indicated that the dominant carbon structure in LCNs evolved from amorphous carbon to nanocrystalline graphite as the carbonization temperature increased. ${ }^{38}$ Ferrari and Robertson explained that during this transition the intensity ratio of the $\mathrm{D}$ and $\mathrm{G}$ bands $\left(I_{\mathrm{D}} / I_{\mathrm{G}}\right)$ is proportional to the square of the crystallite size. $^{50,51}$ Combined with the upshift and the development of asymmetry occurring in the $2 \mathrm{D}$ band, one can conclude that more ordered carbon structures were formed in the LCNs with increasing carbonization temperature.

To assess the electrochemical performance of the LCNs carbonized at different temperatures, we constructed super- capacitors with different LCN electrodes (C800-1400) in an aqueous $6 \mathrm{M} \mathrm{KOH}$ electrolyte (noted as SC-Ls), in which two LCN electrodes were brought in contact with Inconel plates as current collectors and separated with filter paper as demonstrated in Figure 5a. The total mass of both electrodes was $\sim 2 \mathrm{mg}$. The cyclic voltammetry (CV) curves of all the SCLs tested at various scan rates $\left(5-100 \mathrm{mV} \mathrm{s}^{-1}\right)$ are shown in Figure 5b-e. Obviously, CV curves of C1200 and C1400 are more rectangular in shape, suggesting better electrode materials for supercapacitor compared to C800 and C1000. However, the curves of the SC-Ls with C800 and C1000 electrodes have larger integrated area than those with C1200 and $\mathrm{C} 1400$ under the same scan rate, indicating their higher specific capacitances. The specific capacitances of all the LCNs $\left(C_{\text {elec }}\right)$ were calculated via eq 1 and are summarized in Figure 5f. It is found that C800 and C1000 outperformed C1200 and $\mathrm{C} 1400$ at all scan rates. This is converse with the previous 
Table 2. Comparison of the $C_{\text {elec }}$ of the LCNs Prepared in This Study and That of Various Carbon Materials Reported in the Literature

\begin{tabular}{|c|c|c|c|c|c|c|}
\hline materials & $\mathrm{SSA}\left[\mathrm{m}^{2} \mathrm{~g}^{-1}\right]$ & cell configuration & electrolyte & scan rate or current density & $C_{\text {elec }}\left[\mathrm{F} \mathrm{g}^{-1}\right]$ & ref \\
\hline nitrogen-doped carbon & 6 & two-electrode & $6 \mathrm{M} \mathrm{KOH}$ & $1.0 \mathrm{~A} \mathrm{~g}^{-1}$ & 99.4 & 54 \\
\hline activated carbon from banana & 1097 & three-electrode & $1 \mathrm{M} \mathrm{Na}_{2} \mathrm{SO}_{4}$ & $5 \mathrm{mV} \mathrm{s}^{-1}$ & 86 & 55 \\
\hline graphene nanosheet/carbon black & 586 & three-electrode & $6 \mathrm{M} \mathrm{KOH}$ & $10 \mathrm{mV} \mathrm{s}^{-1}$ & 175.0 & 56 \\
\hline modified carbon nanotube & $\mathrm{N} / \mathrm{A}$ & two-electrode & $0.5 \mathrm{M} \mathrm{Na}_{2} \mathrm{SO}_{4}$ & $5 \mathrm{mV} \mathrm{s}^{-1}$ & $<100$ & 57 \\
\hline activated carbon nanofibers & 1389 & three-electrode & $0.5 \mathrm{M} \mathrm{Na}_{2} \mathrm{SO}_{4}$ & $\begin{array}{l}5 \mathrm{mV} \mathrm{s}^{-1} \\
1.0 \mathrm{~A} \mathrm{~g}^{-1}\end{array}$ & $\begin{aligned} & 56.8 \\
\sim & 50\end{aligned}$ & 58 \\
\hline $\begin{array}{l}\text { carbon spheres } / \mathrm{MnO}_{2} \\
\text { green carbon nanofibers }\end{array}$ & $\begin{array}{l}964 \\
797-1672\end{array}$ & $\begin{array}{l}\text { three-electrode } \\
\text { two-electrode }\end{array}$ & $\begin{array}{l}1 \mathrm{M} \mathrm{Na}_{2} \mathrm{SO}_{4} \\
6 \mathrm{M} \mathrm{KOH}\end{array}$ & $\begin{array}{l}1.0 \mathrm{~A} \mathrm{~g}^{-1} \\
5 \mathrm{mV} \mathrm{s}^{-1} \\
10 \mathrm{mV} \mathrm{s}^{-1} \\
0.8 \mathrm{~A} \mathrm{~g}^{-1}\end{array}$ & $\begin{array}{l}\sim 150 \\
241.4 \\
206.7 \\
179.2\end{array}$ & $\begin{array}{l}59 \\
\text { this study }\end{array}$ \\
\hline
\end{tabular}

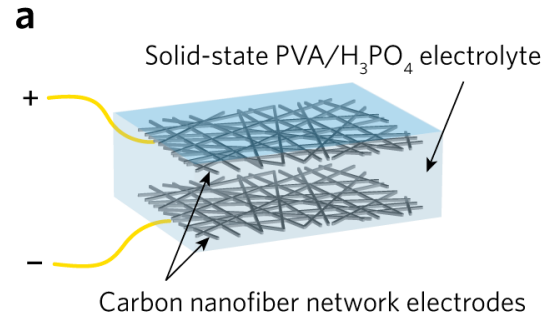

b

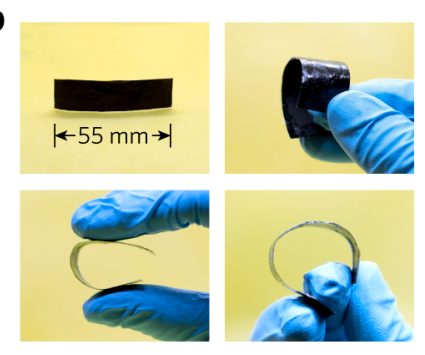

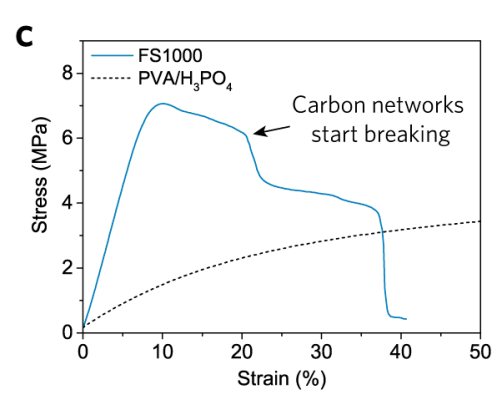

C

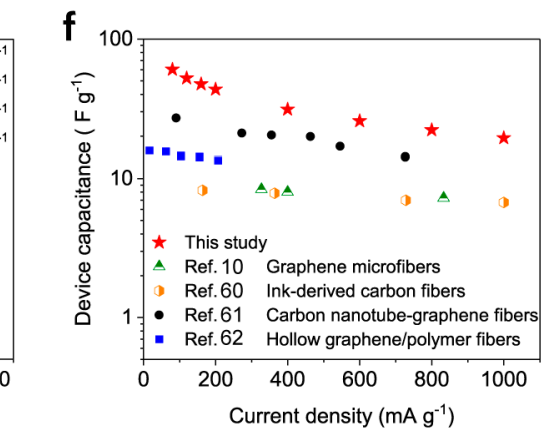

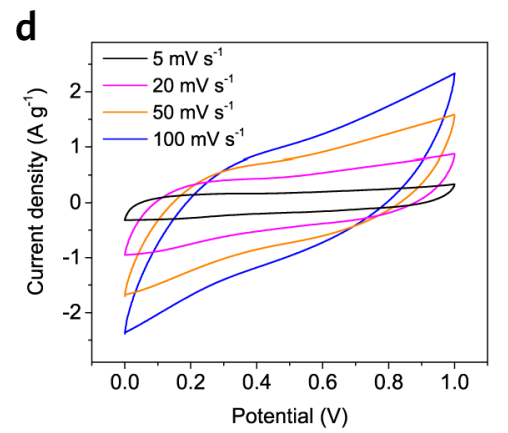

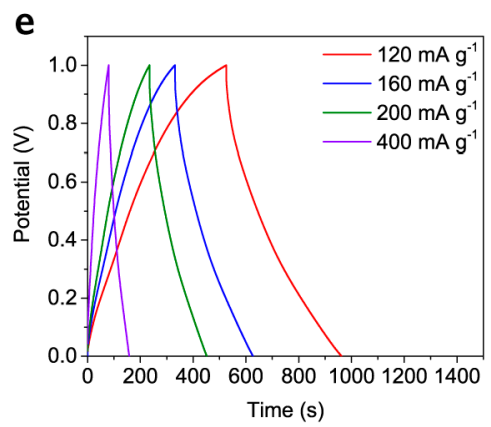

Figure 7. Demonstration, mechanical behavior, and electrochemical performance of FS1000. (a) Schematic of the FS1000 assembled with two C1000 electrodes and solid-state PVA/ $\mathrm{H}_{3} \mathrm{PO}_{4}$ electrolyte. (b) Photographs of the thin and free-standing FS1000 illustrating its flexibility. (c) Representative stress-strain curves of FS1000 (content of C1000 was 5 wt \% of the total device weight) and the $\mathrm{PVA}_{2} \mathrm{H}_{3} \mathrm{PO}_{4}$ electrolyte from tensile testing. (d) Cyclic voltammograms of FS1000 at different scan rates. (e) GCD curves of FS1000 at various current densities. (f) Device capacitance of FS1000 at different current densities compared to other all-solid-state supercapacitors reported in the literature.

results showing that $\mathrm{C} 1200$ and $\mathrm{C} 1400$ had larger SSA, higher carbon contents, and more ordered carbon structure (Table 1 , Figure 2, and Figure 4). To further analyze the reason for this, the contact angles of the LCNs with the aqueous $6 \mathrm{M} \mathrm{KOH}$ electrolyte were measured and are shown in Figure 5f (the ones with distilled water are shown in Figure S8). The contact angle dramatically increased from $11^{\circ}$ to $136^{\circ}$ with the increase in carbonization temperature, which implies that C800 and C1000 were hydrophilic and easily wetted with the aqueous $\mathrm{KOH}$ electrolyte, whereas C1200 and C1400 were much more hydrophobic and therefore difficult to wet. The trend of increasing hydrophobicity is due to the higher carbon content and loss of polar surface groups of the nanofiber networks as revealed by XPS analysis (Figure 2). Therefore, the hydrophobic nature of $\mathrm{C} 1200$ and $\mathrm{C} 1400$ hindered ions of the electrolyte from being adsorbed on the surface of the LCNs, ${ }^{52}$ leading to a reduced $C_{\text {elec}}$.

Galvanostatic charge-discharge (GCD) curves of the SC-Ls at different current densities are shown in Figure S9, and those of the SC-L by using C1000 electrodes at 0.8, 2.1, and $4.2 \mathrm{~A}$ $\mathrm{g}^{-1}$ are shown in Figure 6a as representatives exhibiting good triangular shapes. The $C_{\text {elec }}$ of C800-1400 were also calculated from the related GCD curves (eq 2, Figure S10), which agree with those determined from the $\mathrm{CV}$ curves (Figure 5f). A comparison of the $C_{\text {elec }}$ of the green carbon nanofiber networks developed in this study and the values of various other carbon materials reported in the literature is shown in Table 2. It can be seen that the LCNs prepared from renewable raw materials have very competitive $C_{\text {elec }}$ even compared to the carbon materials decorated with functionalized nanomaterials. However, it needs notifying that according to Figure 6a the Coulombic efficiency of the LCNs was $~ 95 \%$. Reasons behind this can be the charge redistribution due to the unoptimized surface structure of the LCNs and the existence of parasitic Faradaic reactions because of the presence of non-carbon elements in the LCNs. ${ }^{53}$ One should be also noticed that asymmetric electrode materials may also decrease the Coulombic efficiency. 
a

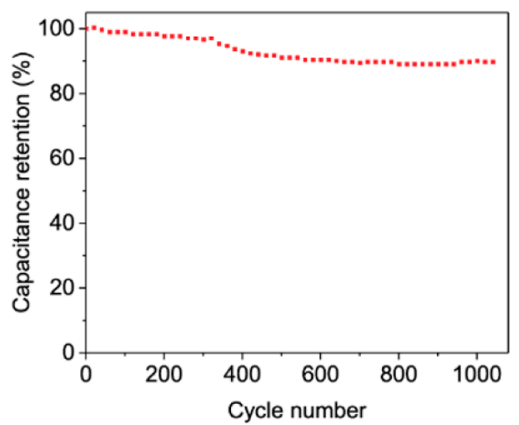

b

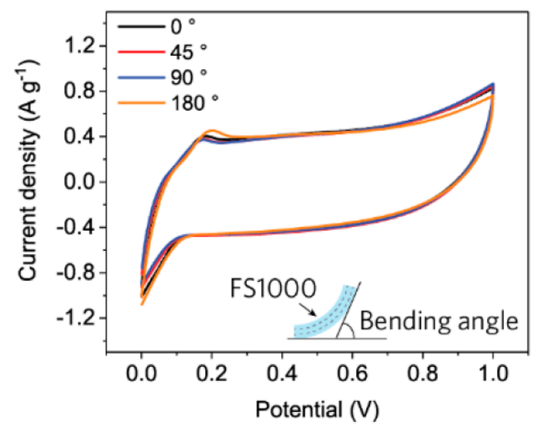

C

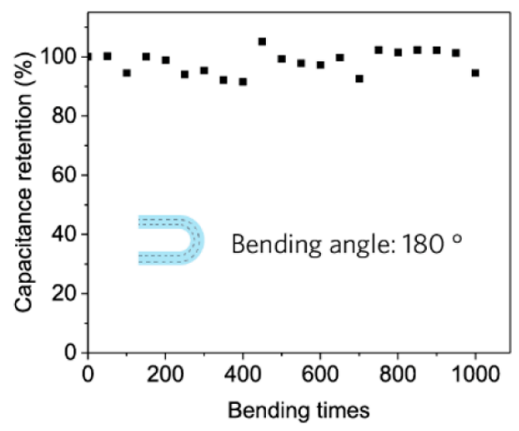

Figure 8. Cycling stability and flexibility analysis of FS1000. (a) Capacitance retention of FS1000 versus the number of cycles according to the GCD measurements. Current density: $1 \mathrm{~A} \mathrm{~g}^{-1}$. (b) Cyclic voltammograms of FS1000 at different bending states of $0^{\circ}, 45^{\circ}, 90^{\circ}$, and $180^{\circ}$. Scan rate: $20 \mathrm{mV} \mathrm{s}^{-1}$. Bending angle was determined by the tangent of both ends of FS1000. (c) Capacitance retention of FS1000 versus the number of times that the FS1000 was bent to $180^{\circ}$. The capacitance was measured at the bending state of $180^{\circ}$.

The energy densities $\left(E_{\mathrm{d}}\right.$, eq 4$)$ and power densities $\left(P_{\mathrm{d}}\right.$, eq 5) of the SC-Ls are displayed in the Ragone plot in Figure $6 \mathrm{~b}$, showing that the SC-Ls performed similarly to other nanostructured carbon-based devices. ${ }^{7}$ The SC-Ls with C800 and $\mathrm{C} 1000$ still had better performance than those with C1200 and C1400 due to the better wetting. The best performing SC$\mathrm{L}$ with $\mathrm{C} 1000$ electrodes demonstrated an energy density of $6.5 \mathrm{Wh} \mathrm{kg}^{-1}$ at a power density of 0.2 or $2.5 \mathrm{Wh} \mathrm{kg}^{-1}$ at $10 \mathrm{~kW}$ $\mathrm{kg}^{-1}$. The Nyquist diagrams (Figure 6c) from the electrochemical impedance spectroscopy (EIS) measurements show that the equivalent series resistance $\left(R_{\mathrm{s}}\right)$ of the SC-Ls, which describes the resistance between the LCNs and the Inconel current collectors as well as the resistance of the electrolyte were rather small, varying between 0.5 and $1.5 \Omega$. However, the charge transfer resistance $\left(R_{\mathrm{ct}}\right)$, which corresponds to the charge transport through the electrode-electrolyte interface, was much higher for $\mathrm{C} 1200$ and $\mathrm{C} 1400$ (17.5 and $19.2 \Omega$, respectively) than $\mathrm{C} 800$ and $\mathrm{C} 1000$, which could be attributed to the superior wetting ability of the latter. Such high charge transfer resistances limited the charge/discharge rates and compromised the overall capacitor performance, especially at higher current densities and frequencies which can be seen in the power performance of the assembled devices.

Under the consideration of both structure and electrochemical performance, $\mathrm{C} 1000$ was chosen for assembling freestanding, flexible all-solid-state supercapacitor devices using $\mathrm{PVA} / \mathrm{H}_{3} \mathrm{PO}_{4}$ as electrolyte as shown in Figure $7 \mathrm{a}$ (coded as FS1000). The use of solid-state electrolyte can not only avoid the risk of the leakage of conventional liquid electrolyte but also eliminate the need for separators which prevent shortcircuiting of the two electrodes in ordinary devices. ${ }^{10}$ As shown in Figure 7b,c, the thin FS1000 device inherited the flexibility of C1000 and showed good mechanical properties which allow it to be integrated to potential wearable electronics. With $5 \mathrm{wt}$ $\%$ of C1000, the elastic modulus of FS1000 was enhanced drastically by 5 times (Table S1 and Figure S11), which is due to the high stiffness of the carbon networks. Meanwhile, the elongation at break of FS1000 reached around 20\% before the carbon networks start breaking (Figure 7c), which further confirms its excellent flexibility.

Similar to CV curves of the SC-L with C1000 as electrodes (Figure 5b-e), all CV curves of FS1000 in Figure 7d are capacitive and symmetric. The gradual loss of their rectangular shape as the scan rate increases was due to the high $R_{\mathrm{s}}$ in the system (according to the EIS results shown in Figure S12).
However, despite the less-efficient charge drift, FS1000 exhibited excellent capacitance according to the GCD tests (Figure 7e), and the corresponding specific capacitance of C1000 in the FS1000 is plotted in Figure S13. Moreover, as a readily assembled supercapacitor device, the device capacitance of FS1000 was also calculated via eq 3 and is shown in Figure $7 \mathrm{f}$. FS1000 had device capacitances of 60.4 and $52.4 \mathrm{~F} \mathrm{~g} \mathrm{~g}^{-1}$ under current densities of 80 and $120 \mathrm{~mA} \mathrm{~g}^{-1}$, respectively. These values outperform many fiber-based supercapacitor devices consisting of various carbon nanomaterials as electrodes and $\mathrm{PVA} / \mathrm{H}_{3} \mathrm{PO}_{4}$ or $\mathrm{PVA} / \mathrm{H}_{2} \mathrm{SO}_{4}$ as the electrolyte (Figure 7 f). ${ }^{10,60-62}$ Furthermore, FS1000 had an energy density of 2.7 $\mathrm{Wh} \mathrm{kg}{ }^{-1}$ while the power density reached $500 \mathrm{~W} \mathrm{~kg}^{-1}$ (Figure S14), which meets the characteristics of typical carbon-based electrostatic double-layer capacitors. ${ }^{63}$ In addition, the quite high $R_{\mathrm{s}}$ of FS1000 shown in Figure S12 was likely arisen from the significantly lower ion conductivity of the solid-state electrolyte as well as the insufficient contact between the current collector and the electrode caused by a thin layer of solid electrolyte present in between. ${ }^{64-66}$ The high $R_{\mathrm{s}}$ can also be evaluated from the notable voltage drop at the beginning of the discharge curves (Figure 7e). These drawbacks limit the current density that can be applied to the supercapacitors and also restrict the electrochemical performance of the supercapacitors. Thus, for future practical applications of the allsolid-state devices, further careful optimization of the electrolyte system is necessary.

To further study the potential of using FS1000 in wearable electronic devices, its cycling stability and flexibility related to the electrochemical performance were analyzed (Figure 8). In the cycling stability test, the assembled FS1000 was charged and discharged continuously with a current density of $1 \mathrm{~A} \mathrm{~g}^{-1}$, and the corresponding $C_{\text {elec }}$ in every cycle was calculated by using eq 2. As shown in Figure $8 \mathrm{a},<10 \%$ of the initial capacitance was lost after 1050 cycles. The loss in the capacitance can be due to the dehydration of the electrolyte caused by resistance-induced heating during the continuous cycling test or some irreversible electrochemical reactions caused by the impurities from the electrode materials. ${ }^{67}$ In the flexibility test, FS1000 was bent to different angles, and the corresponding CV curves under a scan rate of $20 \mathrm{mV} \mathrm{s}^{-1}$ were recorded. It can be seen from Figure $8 b$ that the overall shape of the CV curves did not change even at a harsh bending angle $\left(180^{\circ}\right)$. The slight difference when FS1000 was nearly fully charged or discharged is probably attributed to the 
deformation of the FS1000 which influenced the charge transfer path between the electrode and the electrolyte. Moreover, FS1000 was also bent for $180^{\circ}$ for 1000 times, and the GCD tests were conducted after every 50 times of bending. The capacitance of FS1000 had almost $95 \%$ retention after 1000 times of harsh bending, which also indicates the good connections between the electrodes and electrolyte. ${ }^{68,69}$ Thus, one may conclude that this device is promising to be integrated in a wearable device with further optimization.

\section{CONCLUSION}

In conclusion, we showed that the abundant but highly underutilized lignin can be transformed into electrically conductive, flexible, free-standing, and highly porous LCNs of high SSA that can be used as supercapacitor electrodes with excellent properties. In our methods, the carbonization process was optimized to find advanced microstructure and surface chemistry, which were the key to reach $C_{\text {elec }}$ of up to $241.4 \mathrm{~F}$ $\mathrm{g}^{-1}$, outperforming many other materials. Furthermore, the electrodes showed great mechanical integrity, making them feasible for assembling advanced all-solid-state supercapacitor devices by using $\mathrm{PVA} / \mathrm{H}_{3} \mathrm{PO}_{4}$ electrolytes and having remarkable device capacitances of up to $60.4 \mathrm{~F} \mathrm{~g}^{-1}$. The processing steps of the proposed methods are robust, up and down scalable, and affordable, and the used materials are renewable. Thus, this study paves the road for superb energy devices derived from biomaterials.

\section{EXPERIMENTAL SECTION}

Materials. Lignin (alkali, low sulfonate content, $M_{w}$ of ca. 10000), poly(vinyl alcohol) (PVA, $M_{\mathrm{w}}$ of $89000-98000, \geq 99 \%$ hydrolyzed), potassium hydroxide ( $\mathrm{KOH}$, pellets, $\geq 85 \%$ ), and phosphoric acid solution $\left(\mathrm{H}_{3} \mathrm{PO}_{4}, 85 \mathrm{wt} \%\right.$ in $\left.\mathrm{H}_{2} \mathrm{O}\right)$ were purchased from SigmaAldrich (St. Louis, MO) and used without any further purification.

Electrospinning of Lignin/PVA Solution. A 5 wt \% PVA solution was prepared by adding PVA powder to distilled water and heating to $80^{\circ} \mathrm{C}$ under continuous stirring until a clear solution was obtained. A certain amount of lignin powder was added to the cooled PVA solution, making the lignin/PVA weight ratio $75 / 25$. This blend was then stirred for $2 \mathrm{~h}$. The viscosity, conductivity, and $\mathrm{pH}$ of the solution were tested by using a viscometer (SV-10 Vibro, A\&D Co., Tokyo, Japan), a conductivity meter (S30 SevenEasy, Mettler Toledo, Schwerzenbach, Switzerland), and a $\mathrm{pH}$ meter ( $\mathrm{pH} 21 \mathrm{pH}$ meter, Hanna Instruments, Woonsocket, RI), respectively. The nanofiber networks were formed by using a Fluidnatek LE-10 electrospinning setup (Bioinicia SL, Spain). The newly prepared lignin/PVA solution was transferred to a $12 \mathrm{~mL}$ syringe (HSW NORM-JECT, Henke-Sass, Bremen, Germany), which was connected to a nozzle with a $0.6 \mathrm{~mm}$ capillary through a polytetrafluoroethylene (PTFE) pipe (outer diameter $1 / 8 \mathrm{in}$.). The feeding rate and voltage applied were 0.5 $\mathrm{mL} \mathrm{h}^{-1}$ and $17 \mathrm{kV}$, respectively. The distance between the tip of the capillary and the collector was $20 \mathrm{~cm}$.

Stabilization and Carbonization of Lignin/PVA Nanofiber Networks. The as-spun lignin/PVA nanofiber network was placed on a stainless-steel plate and stabilized in a tube furnace (Nabertherm RHTC-230/15, Nabertherm GmbH, Lilienthal, Germany) in an air atmosphere. The heating procedure was as follows: (i) from room temperature to $100{ }^{\circ} \mathrm{C}$ (heating rate $5{ }^{\circ} \mathrm{C} \mathrm{min}^{-1}$ ) and maintain for 2 h; (ii) from 100 to $180^{\circ} \mathrm{C}$ (heating rate $1{ }^{\circ} \mathrm{C} \mathrm{min}{ }^{-1}$ ) and maintain for $16 \mathrm{~h}$; (iii) from 180 to $220{ }^{\circ} \mathrm{C}$ (heating rate $0.5{ }^{\circ} \mathrm{C} \mathrm{min}{ }^{-1}$ ) and maintain for $8 \mathrm{~h}$. Afterward, the stabilized nanofiber network was placed in a ceramic boat and carbonized at $800,1000,1200$, and 1400 ${ }^{\circ} \mathrm{C}$, respectively, in the same tube furnace under a constant nitrogen flow. A heating rate of $5{ }^{\circ} \mathrm{C} \mathrm{min}-1$ was applied, and the network was maintained at the targeted carbonization temperature for $1 \mathrm{~h}$ before being cooled to room temperature.
Preparation of $\mathrm{FS} 1000$. The $\mathrm{PVA} / \mathrm{H}_{3} \mathrm{PO}_{4}$ electrolyte was prepared by mixing $6 \mathrm{~g}$ of PVA powder and $7 \mathrm{~g}$ of $\mathrm{H}_{3} \mathrm{PO}_{4}$ solution in $59 \mathrm{~g}$ of distilled water. The mixture was heated at $80{ }^{\circ} \mathrm{C}$ under stirring until a clear solution was obtained and then cooled to room temperature. The electrolyte solution was applied to two pieces of $\mathrm{C} 1000$ with same size by the hand-lay-up method, and afterward the assembled device was dried in an oven at $50{ }^{\circ} \mathrm{C}$ for $1 \mathrm{~h}$ to obtain the final solid-state FS1000.

Characterization. Scanning electron microscopy (SEM, Magellan 400 XHR-SEM, FEI Company, Hillsboro, OR) was used to investigate the microstructures of the nanofiber networks. The asspun and stabilized networks were coated with tungsten (Bal-Tec MED 020, Leica, Wetzlar, Germany). The "FibreApp" was used to determine the fiber diameters. ${ }^{70}$ Diameter values from more than 100 fibers (in at least five different areas) were assessed, and the average values were calculated. The chemical composition of the nanofiber networks was studied by using energy-dispersive X-ray spectroscopy (EDX) and X-ray photoelectron spectroscopy (XPS). The EDX tests were conducted by using a scanning electron microscope (JEOL JSM 6460LV, JEOL Ltd., Tokyo, Japan) equipped with a silicon drift detector (Oxford X-MaxN 50 mm2, Oxford Instruments, Oxfordshire, UK). The XPS analysis was performed with a Thermo Fisher Scientific Escalab $250 \mathrm{XI}$ system using an $\mathrm{Al} \mathrm{K} \alpha$ source at $1486.6 \mathrm{eV}$. The data were evaluated by using the Thermo ScientificTM Avantage software. The BET surface analysis was conducted by using an ASAP 2020 Plus surface area analyzer (Micromeritics Instrument Corp., Norcross, GA). The LCNs were degassed at $350{ }^{\circ} \mathrm{C}$ for $1200 \mathrm{~min}$ prior to the $\mathrm{N}_{2}$-adsorption test at $77 \mathrm{~K}$. Thermogravimetric analyses of the nanofiber networks were conducted by using a TA Q500 thermogravimetric analyzer (TA Instruments, New Castle, DE) under a nitrogen atmosphere to $950{ }^{\circ} \mathrm{C}$ at a heating rate of $10{ }^{\circ} \mathrm{C} \mathrm{min}{ }^{-1}$. The carbon structure of the LCNs was analyzed by using a Bruker Senterra dispersive Raman spectroscope (Bruker Corp., Billerica, MA) with a $533 \mathrm{~nm}$ laser beam and a power of $2 \mathrm{~mW}$. Contact angle measurements of the LCNs with the $6 \mathrm{M} \mathrm{KOH}$ electrolyte and distilled water were conducted with an EASYDROP measuring system by using the static sessile method by applying liquid droplets of $4 \mu \mathrm{L}$ to the surface. Images were captured $3 \mathrm{~s}$ after the droplet was placed on the LCNs. The mechanical performances of FS1000 and the PVA/ $\mathrm{H}_{3} \mathrm{PO}_{4}$ electrolyte were characterized by tensile testing using a Shimadzu AG-X universal testing machine (Shimadzu Corp., Kyoto, Japan) with a SLBL $1 \mathrm{kN}$ load cell. At least five specimens from each sample were tested with a gauge length of $10 \mathrm{~mm}$ and a crosshead speed of $5 \mathrm{~mm} \mathrm{~min} \mathrm{~m}^{-1}$ at $22{ }^{\circ} \mathrm{C}$ and $12 \%$ humidity. The electrochemical measurements were performed using a Princeton Applied Research VersaSTAT 3 potentiostat/galvanostat. For electrochemical measurements of SC-Ls, a two-electrode cell consisting of LCN electrodes $\left(10 \times 10 \mathrm{~mm}^{2}\right.$ pieces $)$, a separator made from a Whatman qualitative filter paper (Grade 1, GE Healthcare, Diegem, Belgium), and collector plates made from Inconel 600 superalloy were used. The setup was held together by crocodile jaws during the measurement. Before assembly, the electrodes and separator were wetted with $6 \mathrm{M} \mathrm{KOH}$ electrolyte. For the solid-state supercapacitor, FS1000 was tested directly in a two-electrode configuration without separator, and Inconel 600 superalloy plates were used as current collectors. In the bending and cycle stability test of the FS1000, the current collectors were replaced by flexible and conductive copper foils. The assembled FS1000 was carefully bent to desired angles, and the bending angle was determined by the tangent of both ends as shown in Figure $8 \mathrm{~b}$. The specific gravimetric capacitances of the electrodes $\left(C_{\text {elec }}\right)$ were calculated from the $\mathrm{CV}$ curves according to

$$
C_{\text {elec }}=\frac{2 \cdot A}{\mathrm{~d} V / \mathrm{d} t \cdot \Delta U \cdot m}
$$

where $A$ is the area covered by the CV curve, $\mathrm{d} V / \mathrm{d} t$ is the scan rate, $\Delta U$ is the applied voltage window, and $m$ is the total mass of both electrodes. Alternatively, $C_{\text {elec }}$ can also be calculated from chargedischarge curves: 


$$
C_{\text {elec }}=\frac{4 \cdot I \cdot \Delta t}{\Delta V \cdot m}
$$

where $I$ is the sourced current, $\Delta V$ is the measured voltage window, and $\Delta t$ is the discharge time. Consequently, the device capacitances of supercapacitors $\left(C_{\text {cell }}\right)$ in a two-electrode cell were calculated by using

$$
C_{\text {cell }}=C_{\text {elec }} / 4
$$

The gravimetric energy densities $\left(E_{\mathrm{d}}\right)$ of the supercapacitors were determined by using

$$
E_{\mathrm{d}}=\frac{C_{\text {cell }} \cdot \Delta V^{2}}{2 \times 3.6}
$$

The gravimetric power densities $\left(P_{\mathrm{d}}\right)$ of the supercapacitors were determined from GCD curves by using

$$
P_{\mathrm{d}}=\frac{E_{\mathrm{d}}}{\Delta t}
$$

\section{ASSOCIATED CONTENT}

\section{SI Supporting Information}

The Supporting Information is available free of charge at https://pubs.acs.org/doi/10.1021/acsaem.0c00065.

SEM images of the nanofibers; diameter distributions of the nanofibers; EDX spectra of the LCNs; XPS data of the LCNs; elemental analysis of the dot-like feature; $\mathrm{N}_{2}$ adsorption/desorption of the LCNs; pore size distribution of the LCNs; mass of the electrodes; contact angles of the LCNs; GCD of the LCNs using $\mathrm{KOH}$ as electrolyte; mechanical properties of the FS1000; Nyquist plot of FS1000; specific capacitance and Ragone plot of FS1000 (PDF)

Video of the flexibility test of C1000 (MP4)

\section{AUTHOR INFORMATION}

\section{Corresponding Authors}

Kristiina Oksman - Department of Engineering Sciences and Mathematics, Lulea University of Technology, SE-97187 Lulea, Sweden; Fibre and Particle Engineering Research Group, University of Oulu, FI-90570 Oulu, Finland; Mechanical \& Industrial Engineering (MIE), University of Toronto, Toronto, ON M5S 3G8, Canada; 이이이.org/0000-0003-4762-2854; Email: Kristiina.oksman@ltu.se

Krisztian Kordas - Microelectronics Research Group, University of Oulu, FI-90570 Oulu, Finland; Email: Krisztian.kordas@ oulu.fi

\section{Authors}

Jiayuan Wei - Department of Engineering Sciences and Mathematics, Lulea University of Technology, SE-97187 Lulea, Sweden

Shiyu Geng - Department of Engineering Sciences and Mathematics, Lulea University of Technology, SE-97187 Luleå, Sweden; (1) orcid.org/0000-0003-1776-2725

Olli Pitkänen - Microelectronics Research Group, University of Oulu, FI-90570 Oulu, Finland; 이이.org/0000-00032870-3229

Topias Järvinen - Microelectronics Research Group, University of Oulu, FI-90570 Oulu, Finland

Complete contact information is available at: https://pubs.acs.org/10.1021/acsaem.0c00065

\section{Author Contributions}

K.O. and K.K. conceived and directed the research. J.W. and S.G. conducted most of the experiments and analysis. O.P. and T.P. performed XPS experiments. O.P. and J.W. measured and analyzed the electrochemical properties using liquid-state electrolyte. The manuscript was written through contributions of all authors. All authors have given approval to the final version of the manuscript.

\section{Notes}

The authors declare no competing financial interest.

\section{ACKNOWLEDGMENTS}

We are grateful for the financial support provided by the Swedish Research Council (Carbon Lignin 2017-04240), Swedish strategic research program Bio4Energy, Business Finland (project Grelectronics), and Interreg Nord \& Lapinliitto (project Flexibla Transparenta Ledande Filmer som Electroder). We acknowledge the support received from the Micro- and Nanotechnology Center, University of Oulu. We are thankful for the assistance provided by Peter Ohlen, Dr. Maxime Nöel, and Dr. Mehdi Jonoobi at the Lulea University of Technology in the preliminary stage of this study. The authors appreciate the technical support for the BET measurements provided by Dr. Liang $\mathrm{Yu}$ and Mojtaba Nobandegani at the Lulea University of Technology. Dr. Linn Berglund at the Lulea University of Technology is appreciated for the support for the contact angle measurements. We also thank Dr. Fabiola Vilaseca Morera for the valuable discussions.

\section{REFERENCES}

(1) Wu, Z.; Wang, Y.; Liu, X.; Lv, C.; Li, Y.; Wei, D.; Liu, Z. CarbonNanomaterial-Based Flexible Batteries for Wearable Electronics. Adv. Mater. 2019, 31 (9), 1800716.

(2) Yun, T. G.; Park, M.; Kim, D.-H.; Kim, D.; Cheong, J. Y.; Bae, J. G.; Han, S. M.; Kim, I.-D. All Transparent-Stretchable Electrochromic-Supercapacitor Wearable Patch Device. ACS Nano 2019, 13 (3), 3141-3150.

(3) Du Pasquier, A.; Plitz, I.; Menocal, S.; Amatucci, G. A Comparative Study of Li-Ion Battery, Supercapacitor and Nonaqueous Asymmetric Hybrid Devices for Automotive Applications. J. Power Sources 2003, 115 (1), 171-178.

(4) Aricò, A. S.; Bruce, P.; Scrosati, B.; Tarascon, J.-M.; van Schalkwijk, W. Nanostructured Materials for Advanced Energy Conversion and Storage Devices. Nat. Mater. 2005, 4, 366-377.

(5) Wang, G.; Zhang, L.; Zhang, J. A Review of Electrode Materials for Electrochemical Supercapacitors. Chem. Soc. Rev. 2012, 41 (2), 797-828.

(6) Lu, Q.; Chen, J. G.; Xiao, J. Q. Nanostructured Electrodes for High-Performance Pseudocapacitors. Angew. Chem., Int. Ed. 2013, 52 (7), 1882-1889.

(7) Zhang, L. L.; Zhao, X. Carbon-Based Materials as Supercapacitor Electrodes. Chem. Soc. Rev. 2009, 38 (9), 2520-2531.

(8) Pech, D.; Brunet, M.; Durou, H.; Huang, P.; Mochalin, V.; Gogotsi, Y.; Taberna, P.-L.; Simon, P. Ultrahigh-Power MicrometreSized Supercapacitors Based on Onion-Like Carbon. Nat. Nanotechnol. 2010, 5 (9), 651.

(9) Zhu, Y.; Murali, S.; Stoller, M. D.; Ganesh, K. J.; Cai, W.; Ferreira, P. J.; Pirkle, A.; Wallace, R. M.; Cychosz, K. A.; Thommes, M.; Su, D.; Stach, E. A.; Ruoff, R. S. Carbon-Based Supercapacitors Produced by Activation of Graphene. Science 2011, 332 (6037), 1537-1541.

(10) Meng, Y.; Zhao, Y.; Hu, C.; Cheng, H.; Hu, Y.; Zhang, Z.; Shi, G.; Qu, L. All-Graphene Core-Sheath Microfibers for All-Solid-State, Stretchable Fibriform Supercapacitors and Wearable Electronic Textiles. Adv. Mater. 2013, 25 (16), 2326-2331. 
(11) Pitkänen, O.; Järvinen, T.; Cheng, H.; Lorite, G.; Dombovari, A.; Rieppo, L.; Talapatra, S.; Duong, H.; Tóth, G.; Juhász, K. L.; et al. On-Chip Integrated Vertically Aligned Carbon Nanotube Based Super-and Pseudocapacitors. Sci. Rep. 2017, 7 (1), 16594.

(12) Kordas, K. Grand Challenges in Translational Materials Research. Front. Mater. 2017, 4, 38.

(13) Kadla, J.; Kubo, S.; Venditti, R.; Gilbert, R.; Compere, A.; Griffith, W. Lignin-Based Carbon Fibers for Composite Fiber Applications. Carbon 2002, 40 (15), 2913-2920.

(14) Baker, D. A.; Rials, T. G. Recent Advances in Low-Cost Carbon Fiber Manufacture from Lignin. J. Appl. Polym. Sci. 2013, 130 (2), 713-728.

(15) Geng, S.; Yao, K.; Zhou, Q.; Oksman, K. High-Strength, HighToughness Aligned Polymer-Based Nanocomposite Reinforced with Ultralow Weight Fraction of Functionalized Nanocellulose. Biomacromolecules 2018, 19 (10), 4075-4083.

(16) Sjostrom, E. The Structure of Wood. In Wood Chemistry: Fundamentals and Applications; Sjostrom, E., Ed.; Academic Press: New York, 2013.

(17) Dallmeyer, I.; Kadla, J. F. Lignin-Based Carbon Fibers. In Handbook of Green Materials; Oksman, K., Mathew, A. P., Bismarck, A., Rojas, O. J., Sain, M., Eds.; World Scientific: Singapore, 2014; Vol. 4, pp 25-48.

(18) Norgren, M.; Edlund, H. Lignin: Recent Advances and Emerging Applications. Curr. Opin. Colloid Interface Sci. 2014, 19 (5), 409-416

(19) Kai, D.; Tan, M. J.; Chee, P. L.; Chua, Y. K.; Yap, Y. L.; Loh, X. J. Towards Lignin-Based Functional Materials in a Sustainable World. Green Chem. 2016, 18 (5), 1175-1200.

(20) Aro, T.; Fatehi, P. Production and Application of Lignosulfonates and Sulfonated Lignin. ChemSusChem 2017, 10 (9), 18611877.

(21) Van Heiningen, A. Converting a Kraft Pulp Mill into an Integrated Forest Biorefinery. Pulp and Paper Canada 2006, 107 (6), $38-43$.

(22) Huang, H.-J.; Ramaswamy, S.; Al-Dajani, W. W.; Tschirner, U. Process Modeling and Analysis of Pulp Mill-Based Integrated Biorefinery with Hemicellulose Pre-Extraction for Ethanol Production: A Comparative Study. Bioresour. Technol. 2010, 101 (2), 624631.

(23) Ding, J.; Wang, H.; Li, Z.; Kohandehghan, A.; Cui, K.; Xu, Z.; Zahiri, B.; Tan, X.; Lotfabad, E. M.; Olsen, B. C.; Mitlin, D. Carbon Nanosheet Frameworks Derived from Peat Moss as High Performance Sodium Ion Battery Anodes. ACS Nano 2013, 7 (12), 1100411015 .

(24) Zeng, Z.; Wang, C.; Zhang, Y.; Wang, P.; Seyed Shahabadi, S. I.; Pei, Y.; Chen, M.; Lu, X. Ultralight and Highly Elastic Graphene/ Lignin-Derived Carbon Nanocomposite Aerogels with Ultrahigh Electromagnetic Interference Shielding Performance. ACS Appl. Mater. Interfaces 2018, 10 (9), 8205-8213.

(25) Lallave, M.; Bedia, J.; Ruiz-Rosas, R.; Rodríguez-Mirasol, J. Cordero, T.; Otero, J. C.; Marquez, M.; Barrero, A.; Loscertales, I. G. Filled and Hollow Carbon Nanofibers by Coaxial Electrospinning of Alcell Lignin without Binder Polymers. Adv. Mater. 2007, 19 (23), 4292-4296.

(26) Ruiz-Rosas, R.; Bedia, J.; Lallave, M.; Loscertales, I. G.; Barrero, A.; Rodríguez-Mirasol, J.; Cordero, T. The Production of Submicron Diameter Carbon Fibers by the Electrospinning of Lignin. Carbon 2010, 48 (3), 696-705.

(27) Wang, S.-X.; Yang, L.; Stubbs, L. P.; Li, X.; He, C. LigninDerived Fused Electrospun Carbon Fibrous Mats as High Performance Anode Materials for Lithium Ion Batteries. ACS Appl. Mater. Interfaces 2013, 5 (23), 12275-12282.

(28) Lai, C.; Zhou, Z.; Zhang, L.; Wang, X.; Zhou, Q.; Zhao, Y.; Wang, Y.; Wu, X.-F.; Zhu, Z.; Fong, H. Free-Standing and Mechanically Flexible Mats Consisting of Electrospun Carbon Nanofibers Made from a Natural Product of Alkali Lignin as Binder-Free Electrodes for High-Performance Supercapacitors. J. Power Sources 2014, 247, 134-141.
(29) Dallmeyer, I.; Lin, L. T.; Li, Y.; Ko, F.; Kadla, J. F. Preparation and Characterization of Interconnected, Kraft Lignin-Based Carbon Fibrous Materials by Electrospinning. Macromol. Mater. Eng. 2014, 299 (5), 540-551.

(30) Jin, J.; Yu, B.-j.; Shi, Z.-q.; Wang, C.-y.; Chong, C.-b. LigninBased Electrospun Carbon Nanofibrous Webs as Free-Standing and Binder-Free Electrodes for Sodium Ion Batteries. J. Power Sources 2014, 272, 800-807.

(31) Schreiber, M.; Vivekanandhan, S.; Mohanty, A. K.; Misra, M. Iodine Treatment of Lignin-Cellulose Acetate Electrospun Fibers: Enhancement of Green Fiber Carbonization. ACS Sustainable Chem. Eng. 2015, 3 (1), 33-41.

(32) Oroumei, A.; Fox, B.; Naebe, M. Thermal and Rheological Characteristics of Biobased Carbon Fiber Precursor Derived from Low Molecular Weight Organosolv Lignin. ACS Sustainable Chem. Eng. 2015, 3 (4), 758-769.

(33) Ago, M.; Borghei, M.; Haataja, J. S.; Rojas, O. J. Mesoporous Carbon Soft-Templated from Lignin Nanofiber Networks: Microphase Separation Boosts Supercapacitance in Conductive Electrodes. RSC Adv. 2016, 6 (89), 85802-85810.

(34) Ding, R.; Wu, H.; Thunga, M.; Bowler, N.; Kessler, M. R. Processing and Characterization of Low-Cost Electrospun Carbon Fibers from Organosolv Lignin/Polyacrylonitrile Blends. Carbon 2016, 100, 126-136.

(35) Ma, X.; Kolla, P.; Zhao, Y.; Smirnova, A. L.; Fong, H. Electrospun Lignin-Derived Carbon Nanofiber Mats Surface-Decorated with $\mathrm{MnO}_{2}$ Nanowhiskers as Binder-Free Supercapacitor Electrodes with High Performance. J. Power Sources 2016, 325, $541-548$.

(36) Zhao, Y.; Liu, Y.; Tong, C.; Ru, J.; Geng, B.; Ma, Z.; Liu, H.; Wang, L. Flexible Lignin-Derived Electrospun Carbon Nanofiber Mats as a Highly Efficient and Binder-Free Counter Electrode for Dye-Sensitized Solar Cells. J. Mater. Sci. 2018, 53 (10), 7637-7647.

(37) Hu, S.; Hsieh, Y.-L. Ultrafine Microporous and Mesoporous Activated Carbon Fibers from Alkali Lignin. J. Mater. Chem. A 2013, 1 (37), 11279-11288.

(38) Wei, J.; Geng, S.; Kumar, M.; Pitkänen, O.; Hietala, M.; Oksman, K. Investigation of Structure and Chemical Composition of Carbon Nanofibers Developed from Renewable Precursor. Front. Mater. 2019, 6, 334.

(39) Braun, J.; Holtman, K.; Kadla, J. Lignin-Based Carbon Fibers: Oxidative Thermostabilization of Kraft Lignin. Carbon 2005, 43 (2), 385-394.

(40) Buckley, J. D.; Edie, D. D. Carbon-Carbon Materials and Composites; Noyes Publications: Park Ridge, NJ, 1993; Vol. 1254.

(41) Norberg, I.; Nordström, Y.; Drougge, R.; Gellerstedt, G.; Sjöholm, E. A New Method for Stabilizing Softwood Kraft Lignin Fibers for Carbon Fiber Production. J. Appl. Polym. Sci. 2013, 128 (6), 3824-3830.

(42) Shuguang, H. Xps Nondestructive Depth Analysis Method and Its Application in Cement Based Composite Materials. Cem. Concr. Res. 1994, 24 (8), 1509-1514.

(43) Tanuma, S.; Powell, C.; Penn, D. Calculations of Electron Inelastic Mean Free Paths. Ix. Data for 41 Elemental Solids over the $50 \mathrm{eV}$ to $30 \mathrm{keV}$ Range. Surf. Interface Anal. 2011, 43 (3), 689-713.

(44) Schreiber, M.; Vivekanandhan, S.; Mohanty, A. K.; Misra, M. A Study on the Electrospinning Behaviour and Nanofibre Morphology of Anionically Charged Lignin. Adv. Mater. Lett. 2012, 3, 476.

(45) Kim, C.; Yang, K. Electrochemical Properties of Carbon Nanofiber Web as an Electrode for Supercapacitor Prepared by Electrospinning. Appl. Phys. Lett. 2003, 83 (6), 1216-1218.

(46) Peng, Z.; Kong, L. X. A Thermal Degradation Mechanism of Polyvinyl Alcohol/Silica Nanocomposites. Polym. Degrad. Stab. 2007, 92 (6), 1061-1071.

(47) Tanpichai, S.; Oksman, K. Crosslinked Poly (Vinyl Alcohol) Composite Films with Cellulose Nanocrystals: Mechanical and Thermal Properties. J. Appl. Polym. Sci. 2018, 135 (3), 45710.

(48) Kawamoto, H. Lignin Pyrolysis Reactions. J. Wood Sci. 2017, 63 (2), 117-132. 
(49) Asmadi, M.; Kawamoto, H.; Saka, S. Gas-and Solid/LiquidPhase Reactions During Pyrolysis of Softwood and Hardwood Lignins. J. Anal. Appl. Pyrolysis 2011, 92 (2), 417-425.

(50) Ferrari, A. C.; Robertson, J. Interpretation of Raman Spectra of Disordered and Amorphous Carbon. Phys. Rev. B: Condens. Matter Mater. Phys. 2000, 61 (20), 14095.

(51) Ferrari, A. C.; Robertson, J. Raman Spectroscopy of Amorphous, Nanostructured, Diamond-Like Carbon, and Nanodiamond. Philos. Trans. R. Soc., A 2004, 362 (1824), 2477-2512.

(52) Pandolfo, T.; Ruiz, V.; Sivakkumar, S.; Nerkar, J. General Properties of Electrochemical Capacitors. In Supercapacitors: Materials, Systems and Applications; Beguin, F., Frackowiak, E., Eds.; WileyVCH: Singapore, 2013.

(53) Ferdous, D.; Dalai, A.; Bej, S.; Thring, R. Pyrolysis of Lignins: Experimental and Kinetics Studies. Energy Fuels 2002, 16 (6), 14051412.

(54) Hulicova-Jurcakova, D.; Kodama, M.; Shiraishi, S.; Hatori, H.; Zhu, Z. H.; Lu, G. Q. Nitrogen-Enriched Nonporous Carbon Electrodes with Extraordinary Supercapacitance. Adv. Funct. Mater. 2009, 19 (11), 1800-1809.

(55) Subramanian, V.; Luo, C.; Stephan, A. M.; Nahm, K.; Thomas, S.; Wei, B. Supercapacitors from Activated Carbon Derived from Banana Fibers. J. Phys. Chem. C 2007, 111 (20), 7527-7531.

(56) Yan, J.; Wei, T.; Shao, B.; Ma, F.; Fan, Z.; Zhang, M.; Zheng, C.; Shang, Y.; Qian, W.; Wei, F. Electrochemical Properties of Graphene Nanosheet/Carbon Black Composites as Electrodes for Supercapacitors. Carbon 2010, 48 (6), 1731-1737.

(57) Shi, K.; Ren, M.; Zhitomirsky, I. Activated Carbon-Coated Carbon Nanotubes for Energy Storage in Supercapacitors and Capacitive Water Purification. ACS Sustainable Chem. Eng. 2014, 2 (5), 1289-1298.

(58) Wang, J.-G.; Yang, Y.; Huang, Z.-H.; Kang, F. A HighPerformance Asymmetric Supercapacitor Based on Carbon and Carbon- $\mathrm{MnO}_{2}$ Nanofiber Electrodes. Carbon 2013, 61, 190-199.

(59) Lei, Z.; Zhang, J.; Zhao, X. Ultrathin $\mathrm{MnO}_{2}$ Nanofibers Grown on Graphitic Carbon Spheres as High-Performance Asymmetric Supercapacitor Electrodes. J. Mater. Chem. 2012, 22 (1), 153-160.

(60) Fu, Y.; Cai, X.; Wu, H.; Lv, Z.; Hou, S.; Peng, M.; Yu, X.; Zou, D. Fiber Supercapacitors Utilizing Pen Ink for Flexible/Wearable Energy Storage. Adv. Mater. 2012, 24 (42), 5713-5718.

(61) Qu, G.; Cheng, J.; Li, X.; Yuan, D.; Chen, P.; Chen, X.; Wang, B.; Peng, H. A Fiber Supercapacitor with High Energy Density Based on Hollow Graphene/Conducting Polymer Fiber Electrode. Adv. Mater. 2016, 28 (19), 3646-3652.

(62) Yu, D.; Goh, K.; Wang, H.; Wei, L.; Jiang, W.; Zhang, Q.; Dai, L.; Chen, Y. Scalable Synthesis of Hierarchically Structured Carbon Nanotube-Graphene Fibres for Capacitive Energy Storage. Nat. Nanotechnol. 2014, 9 (7), 555.

(63) Lu, M. Supercapacitors: Materials, Systems, and Applications; John Wiley \& Sons: 2013.

(64) Moon, W. G.; Kim, G.-P.; Lee, M.; Song, H. D.; Yi, J. A Biodegradable Gel Electrolyte for Use in High-Performance Flexible Supercapacitors. ACS Appl. Mater. Interfaces 2015, 7 (6), 3503-3511.

(65) Kaempgen, M.; Chan, C. K.; Ma, J.; Cui, Y.; Gruner, G. Printable Thin Film Supercapacitors Using Single-Walled Carbon Nanotubes. Nano Lett. 2009, 9 (5), 1872-1876.

(66) Anothumakkool, B.; Bhange, S. N.; Badiger, M. V.; Kurungot, S. Electrodeposited Polyethylenedioxythiophene with Infiltrated Gel Electrolyte Interface: A Close Contest of an All-Solid-State Supercapacitor with Its Liquid-State Counterpart. Nanoscale 2014, 6 (11), 5944-5952.

(67) Yang, Y.; Huang, Q.; Niu, L.; Wang, D.; Yan, C.; She, Y.; Zheng, Z. Waterproof, Ultrahigh Areal-Capacitance, Wearable Supercapacitor Fabrics. Adv. Mater. 2017, 29 (19), 1606679.

(68) Kou, L.; Huang, T.; Zheng, B.; Han, Y.; Zhao, X.; Gopalsamy, K.; Sun, H.; Gao, C. Coaxial Wet-Spun Yarn Supercapacitors for High-Energy Density and Safe Wearable Electronics. Nat. Commun. 2014, 5, 3754.
(69) Pu, X.; Li, L.; Liu, M.; Jiang, C.; Du, C.; Zhao, Z.; Hu, W.; Wang, Z. L. Wearable Self-Charging Power Textile Based on Flexible Yarn Supercapacitors and Fabric Nanogenerators. Adv. Mater. 2016, 28 (1), 98-105.

(70) Usov, I.; Mezzenga, R. Fiberapp: An Open-Source Software for Tracking and Analyzing Polymers, Filaments, Biomacromolecules, and Fibrous Objects. Macromolecules 2015, 48 (5), 1269-1280. 